\title{
A paisagem percebida no pulsar do Complexo Ambiental Sacaí, Baixo Rio Branco, Roraima, Brasil
}

\author{
The perceived landscape in the pulsar of the Sacai \\ Environmental Complex, Baixo rio Branco, Roraima, \\ Brazil \\ Thiago José Costa Alves ${ }^{a}$ \\ Sandra do Nascimento Noda ${ }^{b}$ \\ Juliane Marques de Souzac \\ ${ }^{a}$ Professor do Curso de Turismo, Universidade Estadual de Roraima, Boa Vista, RR, Brasil. \\ End. Eletrônico: thiago.uerr@gmail.com \\ ${ }^{b}$ Universidade Federal do Amazonas, Manaus, AM, Brasil (In memoriam). \\ End. Eletrônico: hnoda@inpa.gov.br
}

'Professora do Curso de Ciências Biológicas e do Mestrado Profissional em Ensino de Ciências, Universidade Estadual de Roraima, Boa Vista, RR, Brasil. End. Eletrônico: juliane.marques.souza@gmail.com

doi:10.18472/SustDeb.v9n3.2018.18379

\section{RESUMO}

Os agroecossistemas amazônicos são parte de uma estrutura complexa, a Amazônia, e apresentam estruturas têmporo-espaciais diretamente relacionadas ao ambiente vivificado e ao saber imaterial dos agricultores. Este estudo teve por objetivo a compreensão do movimento de conservação da autopoiese da vida no Complexo Ambiental Sacaí, Caracaraí, Roraima, Brasil, a partir dos processos antitéticos de delineamento têmporo-espacial do pulso das águas, manifestos a partir das paisagens de seca e de cheia. O fluir do Complexo Ambiental Sacaí traz consigo temporalidade e espacialidade, as quais podem ser reveladas a partir das diversas visões de mundo sobre as unidades de paisagem. Apesar de se mostrarem de forma concreta, essas unidades de paisagem somente são possíveis de serem acessadas desde o caminho imaterial, resultado do vivificado. Foram utilizados como instrumentos de coleta de dados, entrevista com roteiro prévio, mapa de recursos naturais e reuniões espontâneas de validação nas varandas (Revv).

Palavras-chave: Comunidades Ribeirinhas; Agroecossistemas; Autopoiese; Imaterialidade;

\begin{abstract}
Amazonic agroecosystems are part of a complex structure, the Amazon forest. They are composed by space-time structures that are related to the vivified environment and to the farmers' immaterial knowledge. This study aims to understand the conservation movement of autopoiesis of life in the Sacai Environmental Complex, Caracarai, Roraima. Brazil, from the antithetic process of space-time design of water pulse, exposed from the drought and flood landscapes. This movement brings temporality and spatiality which can be revealed through the variety of perceptions about landscape unit. Even though
\end{abstract}


they are easily observable, these landscapes unities can only be accessed by the immaterial way as a result of the vivified. To achieve this, semi-structured interviews, natural resources map and REVV (Spontaneous validation meetings) were undertaken.

Keywords: Riverside Community; Agroecossystems; Autopoesis; Imaterial.

\section{INTRODUÇÃO}

O fluir no Complexo Ambiental Sacaí traz consigo o movimento da paisagem que compõe os agroecossistemas familiares. O tempo é medido pelo pulsar das águas, onde novas feições se apresentam. O Complexo Ambiental Sacaí localiza-se no Baixo Rio Branco, sul do município de Caracaraí (Latitude: +0:44:76; Longitude: -61:51:85), à margem direita do Rio Branco (Figura 1). O Rio Branco é o principal afluente da bacia do Rio Amazonas no estado de Roraima (FEMACT, 2007a, p.19).

Este estudo teve como objetivo identificar a percepção ambiental dos moradores dos agroecossistemas do Complexo Ambiental Sacaí em relação ao pulso das águas e ao movimento das unidades de paisagem lá existentes. O desenho utilizado para a pesquisa foi o estudo de múltiplos casos (YIN, 2014, p. 70) onde a unidade de análise foi constituída pelos agroecossistemas familiares do Complexo Ambiental Sacaí, Baixo Rio Branco, Caracaraí, Roraima. Os sujeitos da pesquisa foram selecionados de forma aleatória. As ferramentas e técnicas foram conduzidas primeiramente a partir de uma entrevista com roteiro prévio aplicada em nove famílias nucleares. O presente estudo foi submetido e aprovado pelo Conselho de Ética em Pesquisa, na Plataforma Brasil, e está registrado com o número CAAE: 36319014.6.000.

Todos os sujeitos citados a partir de dísticos deverão ter suas iniciais grafadas, assim como idade e localidade de moradia. Ainda na primeira etapa de coleta, construiu-se, coletivamente, um Mapa de Recursos Ambientais (VERDEJO, 2006) referente ao ambiente percebido pelos agricultores familiares do Complexo Ambiental Sacaí.

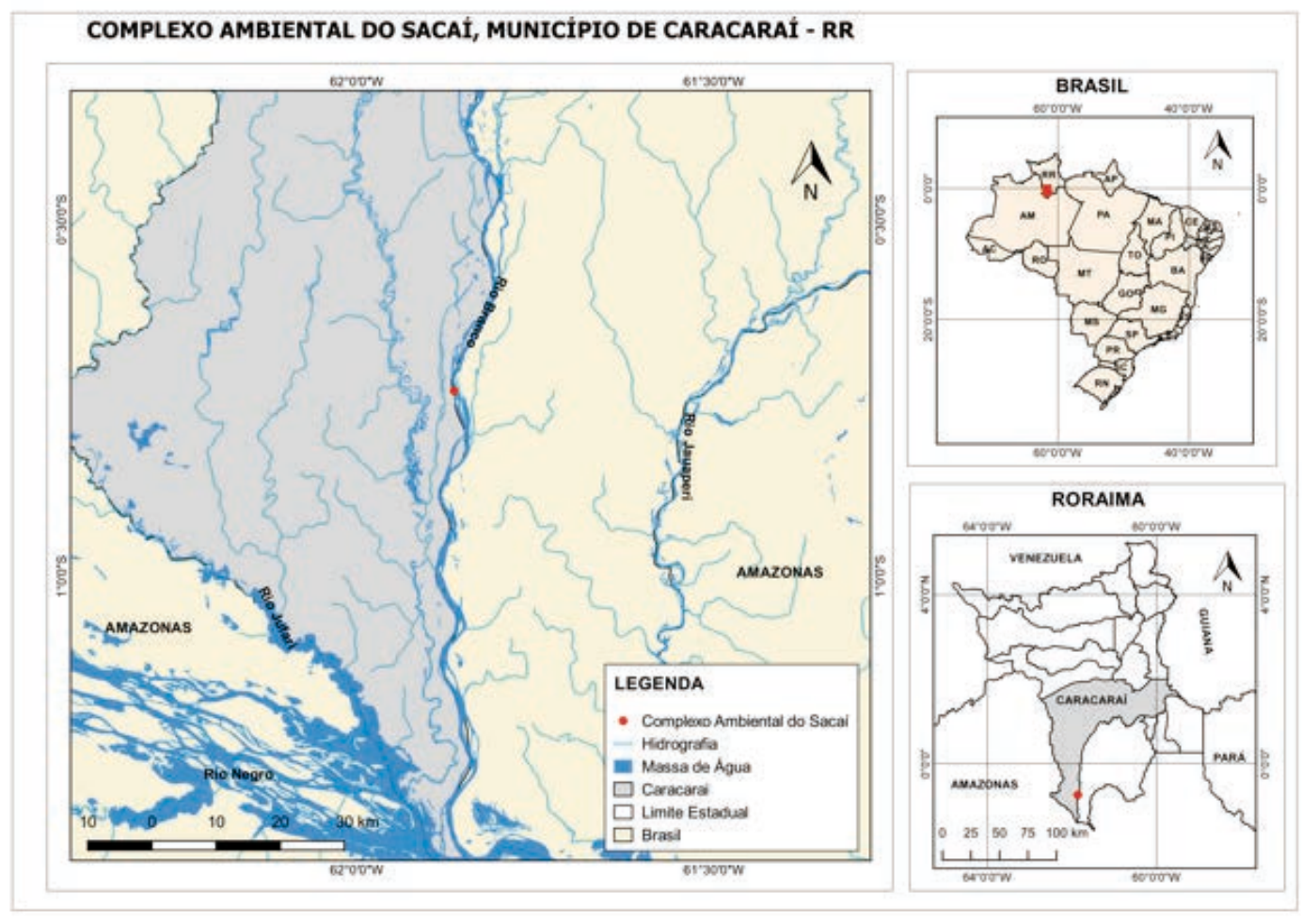

Figura 1 - Mapa de localização da sede do Complexo Ambiental Sacaí Caracaraí, Roraima, Brasil.

Fonte: Organizado pelos autores. 
Na segunda fase de coleta foram aplicadas entrevistas coletivas de validação a partir da ferramenta caracterizada como reuniões espontâneas de validação nas varandas (Revv), com o objetivo de validar todas as evidências coletadas na fase anterior. Nessa parte da coleta de evidências foi solicitado aos sujeitos que descrevessem o comportamento das unidades de paisagem de acordo com a variável têmporo-espacial. Foram utilizadas ferramentas descritivas para entendimento da dinâmica das unidades de paisagem, tais como mapas mentais, imagens de geoprocessamento e entrevista.

O presente artigo está dividido em seis seções, são elas: a) "Introdução", local onde são descritos uma breve contextualização, objetivos e procedimentos metodológicos; b) "A paisagem do Complexo Ambiental Sacaí", onde é constituída a partir do entrelaçamento entre evidências primárias de coleta e análise bibliográfica a categoria de análise "unidade de paisagem" à luz da complexidade sistêmica; c) "A organização da paisagem desde o pulso das águas", nessa parte do estudo são tratadas as interações materiais e imateriais das unidades de paisagem desde a têmporo-espacialidade pulsar das águas; d) "A paisagem de seca", nessa seção é considerada a possibilidade descritiva das unidades de paisagem de seca desde as visões de mundo dos agricultores familiares do Complexo Ambiental Sacaí; e) "A paisagem de cheia", nessa parte do estudo são caracterizadas as unidades de paisagem do período de cheia desde as visões de mundo dos agricultores familiares do Complexo Ambiental Sacaí e; f) "Considerações finais", nessa seção são pontuados os principais direcionamentos e avanços da pesquisa desde a relação de reconhecimento do saber ambiental.

\section{A PAISAGEM DO COMPLEXO AMBIENTAL SACAÍ}

Em estudo empreendido no Careiro da Várzea, Amazonas, Sternberg (1998) apresenta a forma como as águas são elementos definidores da dinâmica da paisagem no contexto amazônico:

[...] as variações sazonais do nível das águas obrigam o homem a constantes ajustamentos; é através dessas pulsações da paisagem que mais claramente aparecem as vinculações da coletividade com o meio. $O$ ciclo anual de enchentes e vazantes, ao qual se subordinaram necessariamente as atividades do grupo humano, rompe a relativa monotonia da planície e cria como que duas paisagens diferentes (STERNBERG, 1998, p. 245).

As duas paisagens distintas, a qual se refere Sternberg (1998), estão relacionadas aos períodos hidrológicos do rio, de cheia e de seca. Para Junk (1989, p. 110), o pulso de inundação é a principal força natural responsável pela existência, produtividade e interações da biota com os sistemas das várzeas dos rios. Essa mesma dinâmica se apresenta no Complexo Ambiental Sacaí, assumindo, contudo, um desenho próprio. Em um dístico é possível identificar como essa relação temporal é estabelecida pelo pulso das águas: "aqui quem manda é a água, a água e a necessidade" (S. Z., 31 anos, Sacaí).

Segundo dados fluviométricos do CPRM (2017), da estação de Santa Maria do Boiaçu (Latitude: -0:30:19 e Longitude: -61:47:11), a partir de medições desde o ano de 1972 até o ano de 2017, é possível afirmar que o Complexo Ambiental Sacaí apresenta quatro estações anuais, que podem ser descritas da seguinte forma: a) período de enchente, curva ascendente de volume das águas entre os meses de março a maio; b) período de cheia, com padrão mais estável com alto nível das águas, entre os meses de maio a julho; c) período de vazante, curva descendente de volume das águas entre os meses de julho e novembro e; d) período de seca, culturalmente explicitado por "seca", com padrão estável em baixo nível das águas, entre os meses de novembro e março (Figura 2A).

O padrão pluviométrico no Complexo Ambiental Sacaí, por sua vez, segue a seguinte distribuição: a) período com ascendência no volume de chuvas entre os meses de janeiro e março; b) período com maior volume de chuvas entre os meses de março e julho; c) período descendente no volume de chuvas entre os meses de julho e setembro e d) período com menor volume de chuvas entre os meses de setembro e janeiro (Figura 2B). 


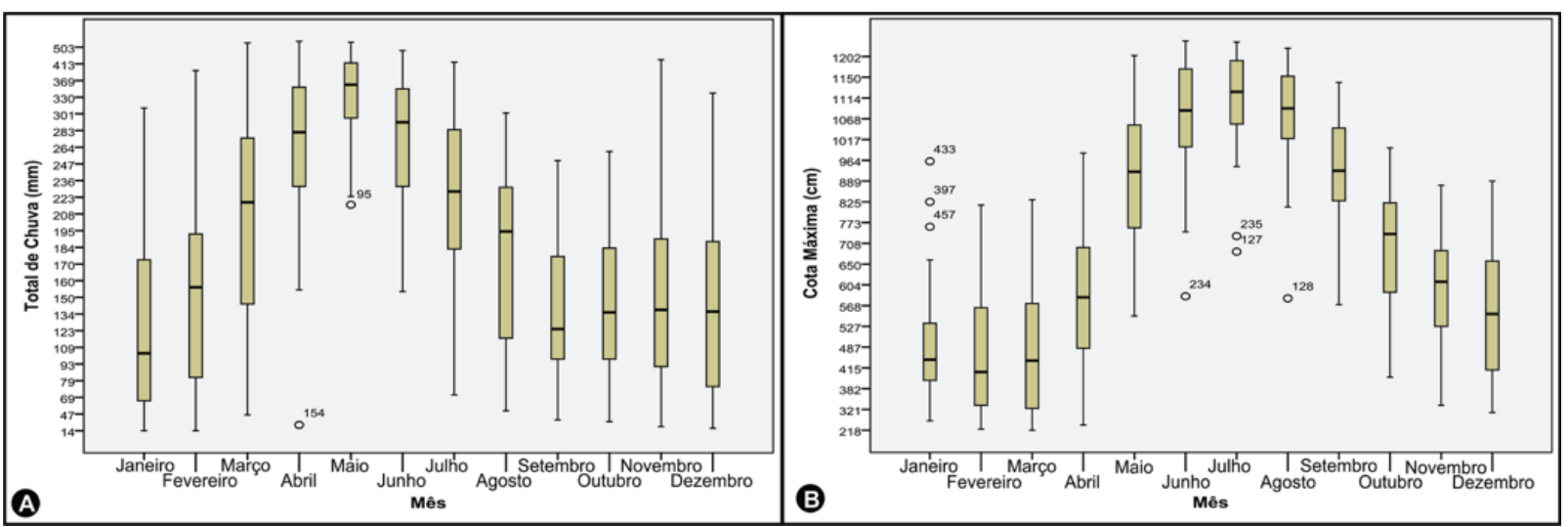

Figura 2 - Dados pluviométricos (CPRM, 2017) da estação de Santa Maria do Boiaçu, Caracaraí, Roraima (A) e dados fluviométricos da estação de Santa Maria do Boiaçu, Caracaraí, Roraima (B).

Fonte: Organizado pelos autores.

A análise dos dados do CPRM (2017) sugere a existência de relação entre os períodos de chuva e o aumento do nível das águas. Entre os meses de março e abril ocorre o aumento dos índices pluviométricos e, como consequência desse fato, o rio começa a apresentar maiores volumes a partir do mês de maio.

No entanto, não somente a chuva é responsável pela alteração do volume hídrico do Rio Branco. A música "Roraimeira", de autoria de Zeca Preto, traz em um dos seus trechos a seguinte relação: "[...] o teu importante rio chamado Branco, sem preconceito em um Negro ele aflui." Essa relação ilustrada pelo compositor na música explicita um saber também compartilhado pelos moradores do Complexo Ambiental Sacaí. O dístico reproduzido a seguir explicita a compreensão da relação existente entre o período de vazante do Rio Branco e a diminuição do volume das águas do Rio Negro, o qual se apresenta da seguinte forma:

[...] se choveu muito para cá e se estiver secando o Rio Negro, não enche para cá não, só lá para cima. A cheia aqui só faz dar uma paradinha quando tá puxando bem no Rio Negro. (S. J. Q.; anos, Sacaí).

O exposto sugere que o regime das águas de um rio (des)ordena o regime das águas de um outro rio. Nesse sentido, a estreita relação existente entre dois rios de um mesmo sistema hídrico "põe em xeque" a possibilidade de reconhecimento do movimento das águas isoladamente. Não obstante, as águas atuam como guias no delineamento das paisagens, sendo a compreensão de sua dinâmica fundamental para o entendimento do sistema ambiental.

Para Metzger (2001, p. 4), ecossistemas, cobertura, uso e ocupação são elementos que compõem o conjunto interativo formador da paisagem, sendo esta um mosaico heterogêneo formado por unidades de paisagem interativas, fruto de interferência têmporo/espacial, em uma determinada escala de compreensão.

No entanto, a compreensão das unidades de paisagem segue diferentes caminhos teóricos, os quais por vezes consideram somente a variável espacial em sua estrutura científica. Para Balée (2017, p. 182), em seu quarto postulado em relação aos avanços da história ecológica, o autor admite que a cultura no ambiente possa ser reconhecida a partir da paisagem, a qual estabelece como paisagem cultural. Para isso, existe a necessidade de que as interações com o ambiente sejam apreendidas desde as diversas unidades de vida humanas e não humanas no ambiente.

Já Claval (2014, p. 313) afirma que a paisagem reúne três patamares de observação, as quais o autor classifica como: a) funcionalidade, onde as disposições físicas e econômicas podem ser acessadas à primeira vista, assim como qualidade do solo e água; b) parâmetros históricos, os quais remetem ao conjunto de informações de origem e que por ventura dão significado ao conjunto de interações 
acessados no plano da funcionalidade e; c) parâmetros utilitários e de significados, onde o uso e os signos são característicos e caracterizadores do lugar, tal como as condições toponímicas (batismo dos lugares).

Para Carlos (2007, p. 33), a paisagem é uma obra coletiva com ritmo próprio e vai além da perspectiva geográfica. É ligada diretamente à produção do espaço como produto das relações humanas e revela não somente a reprodução material, mas a imaterialidade. Esta última é responsável pelo processo (re)construtivo impregnado de vida como, por exemplo, mistérios, beleza, sinais, símbolos e alegorias, todos carregados de significado e memória (CARLOS, 2007, p. 33).

Em contraponto aos dizeres de Carlos (2007), Tuan (2012) afirma que apesar da unidade de paisagem surgir como obra de uma coletividade, as interações entre individualidades devem ser asseguradas na sua interpretação:

[...] entre os indivíduos, as variações físicas externas são notáveis, mas são menores quando comparadas com as diferenças internas. [...] as atividades em relação à vida e ao meio ambiente refletem necessariamente variações individuais biogeoquímicas e fisiológicas (TUAN,2012, p. 5).

A individualidade para Tuan (2012) deve ser identificada e desvelada como o caminho para a imaterialidade. Para tal, o autor sugere a categoria de análise "visões de mundo" a qual afirma estar relacionada aos conceitos de: a) percepção e; b) atitude. Para o autor, a percepção é tanto a resposta aos estímulos externos como a atividade proposital. Certos fenômenos são claramente registrados, relegados como restritos e/ou bloqueados. Por atitude, o autor considera ser uma postura cultural, com maior estabilidade do que a percepção, formada por uma longa sucessão de percepções, a qual é constituída desde as experiências. Nesse sentido, a visão de mundo é uma experiência conceitualizada sobre determinado aspecto, a qual se baseia em um sistema de crenças daquilo que foi vivificado e, assim, estruturada de forma particular e objetiva (TUAN, 2012, p. 5).

Neste estudo considera-se que a imaterialidade é parte inerente ao plano da espacialidade, ou seja, os saberes relacionados ao uso e ocupação do espaço são também reveladores na descrição e no reconhecimento da paisagem.

Nesse contexto, o movimento das águas desenha para o Complexo Ambiental Sacaí duas paisagens, tais quais aquelas descritas por Sternberg (1998) e aqui identificadas por paisagem de cheia e de seca. O Complexo Ambiental Sacaí permeia como a principal referência de paisagem sendo as paisagens de cheia e de seca formadas por um mosaico de diversas unidades de paisagem.

Como primeiro passo à sistematização do conhecimento acerca do tema, foi aplicada a ferramenta "mapa de recursos ambientais" (VERDEJO, 2006, p. 30), com o objetivo de construir um mapa mental coletivo de toda a localidade (Figuras $3 \mathrm{~A}$ e B). $\mathrm{O}$ produto dessa ferramenta figura como uma fiel fonte de informação da ocupação e uso do espaço, a qual permite a compreensão do ambiente a partir da organização coletiva das visões de mundo, expressas a partir de um mapa mental. 


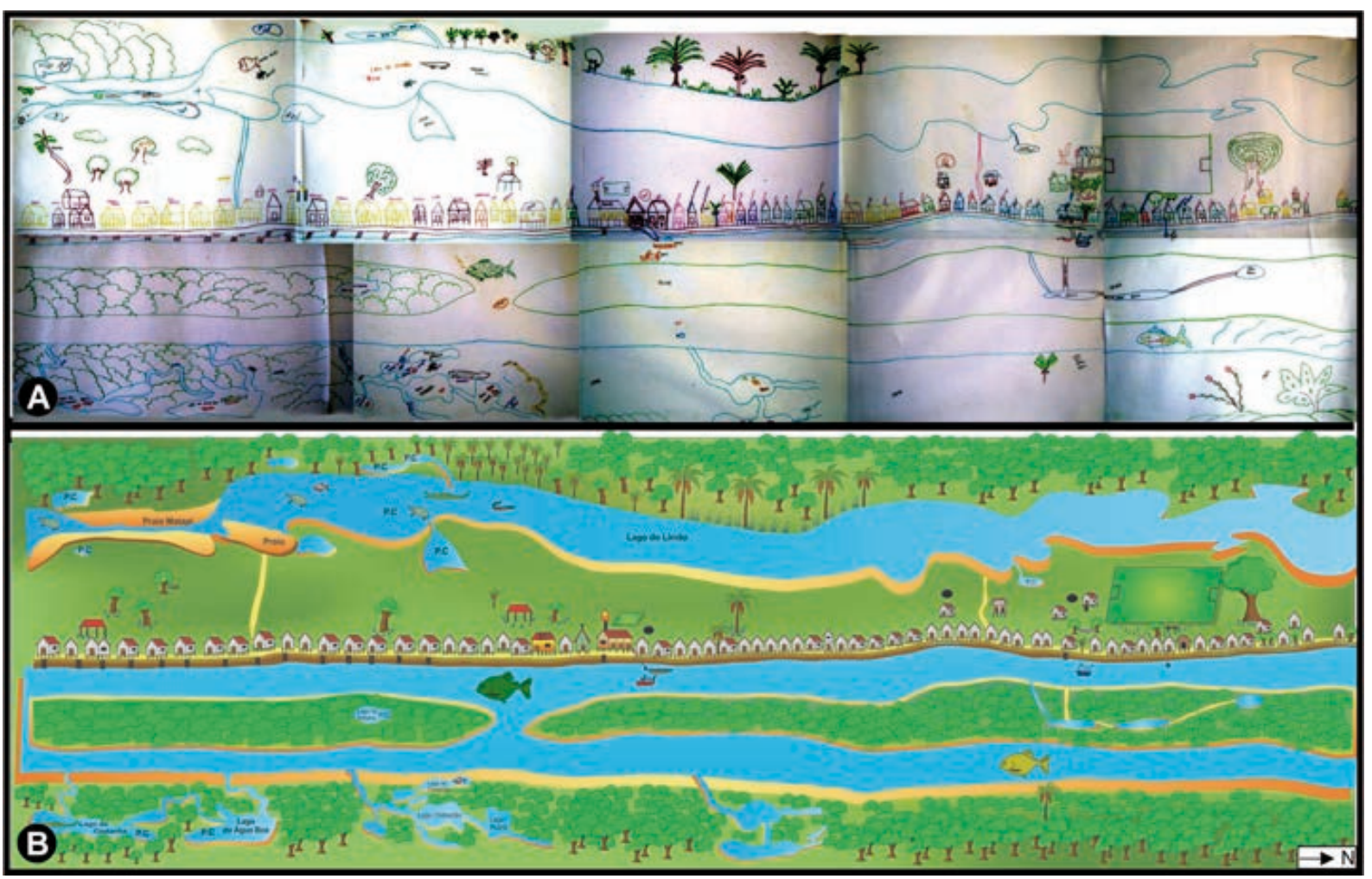

Figura 3 - Mapa de Recursos ambientais emic do Complexo Ambiental Sacaí (A); mapa de recursos ambientais etic do Complexo Ambiental Sacaí produzido coletivamente pelas famílias agricultoras em dez folhas de cartolina (B).

Fonte: Organizado pelos autores.

A paisagem do Complexo Ambiental Sacaí acessada preliminarmente pelo mapa de recursos ambientais se revela complexa e dinâmica. A disposição e localização das casas, a ocorrência de lagos, as ilhas, o capital material do trabalho, os recursos ambientais, entre outros, dão uma visão geral e coletiva do todo, de maneira a permitir um aprofundamento da compreensão do local desde os dísticos e de dados secundários da literatura existente.

\section{A ORGANIZAÇÃO DA PAISAGEM DESDE O PULSO DAS ÁGUAS}

Como estratégia de campo, estabelecida desde a possibilidade de aproximação do real, notou-se que a referência de altura ocupava espaço elucidativo na composição do discurso dos sujeitos para explicar a recursividade da paisagem no Complexo Ambiental Sacaí. Nesse sentido, essa variável surge como importante evidência para compreensão da organização dessa paisagem e sua configuração nos períodos de cheia e de seca, uma vez que revela a possibilidade de exposição e/ou submersão de porções de terra em virtude do pulso das águas.

Durante a aplicação de uma ferramenta em grupo focal, construiu-se um esboço de perfil altimétrico (Figura 4) do Complexo Ambiental Sacaí, onde foi possível identificar os seguintes elementos de elevação do terreno, são eles: a) terra firme (Tf) e; b) a várzea. (Va). No caso da várzea, as descrições apontaram para elevações diferenciadas, em porções mais altas (Va) e porções mais baixas (Vb).

O modo como os sujeitos utilizam os conhecimentos sobre altimetria apresenta relação direta com a forma como percebem a paisagem no Complexo Ambiental Sacaí em períodos de cheia e de seca. Pela descrição dos sujeitos, a várzea caracteriza-se basicamente pelas porções de terra inundáveis, sendo que a várzea mais baixa é aquela que primeiro é tomada por águas e a várzea mais alta a que terá suas porções de terra tomadas tardiamente. Por sua vez, a terra firme caracteriza-se por porções de terra 
que nunca sofrem inundações em virtude de sua elevação.

Nesse sentido, as várzeas e as terras firmes compõem o primeiro plano de configuração das unidades de paisagem no Complexo Ambiental Sacaí e pertencem, simultaneamente, à paisagem de cheia e à paisagem de seca, as quais serão tratadas detalhadamente a seguir.

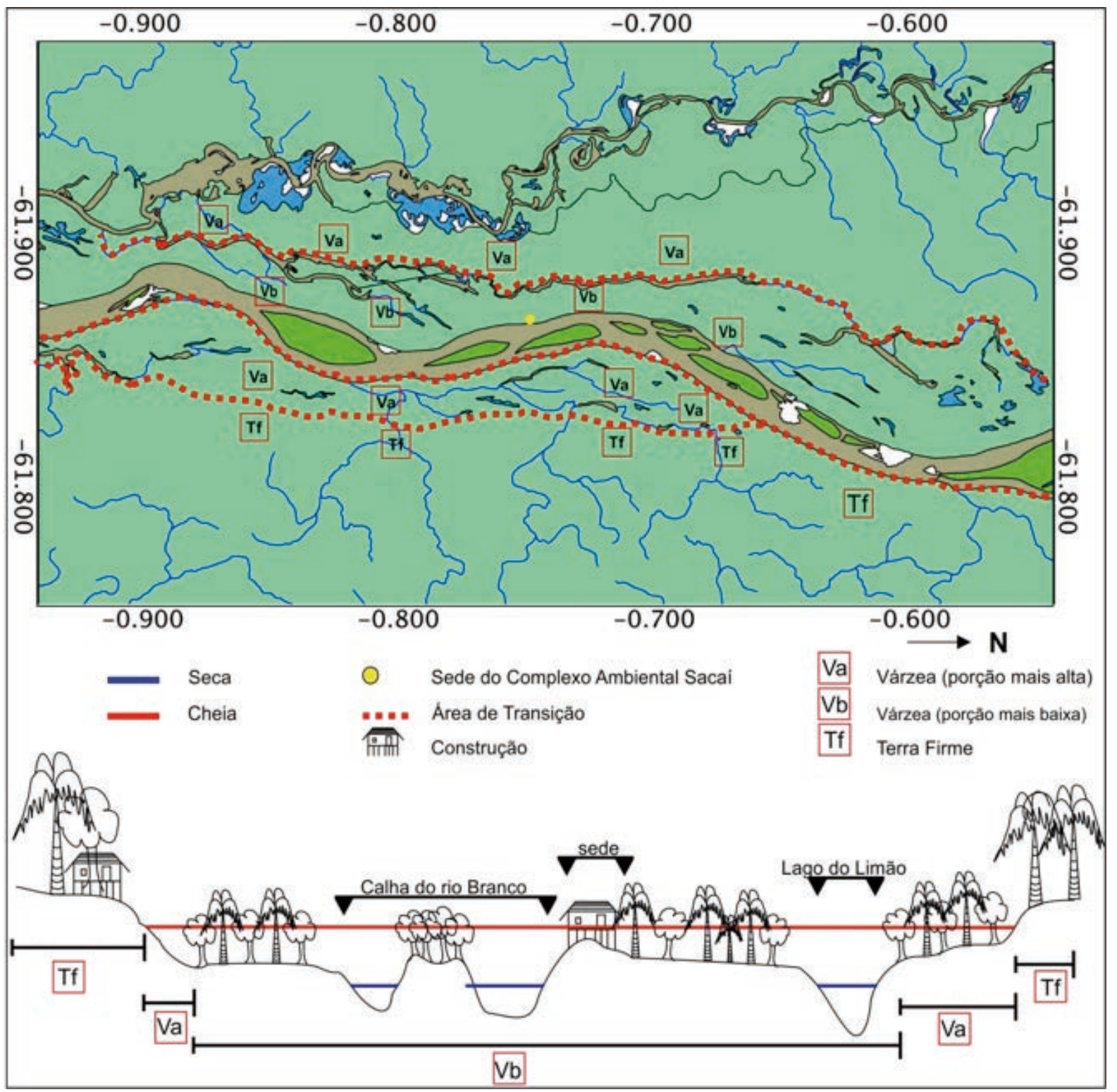

Figura 4 - Complexo Ambiental Sacaí e suas unidades de paisagem; Perfil, área recortada, do pulso das águas no Complexo Ambiental Sacaí.

Fonte: Organizado pelos autores.

\section{A PAISAGEM DE SECA}

A paisagem de seca no Complexo Ambiental Sacaí caracteriza-se por revelar grandes extensões de terra. As visões de mundo dos sujeitos apontam para a existência das seguintes unidades nesta paisagem: a) o rio; b) as praias; c) o paranã; d) as várzeas; e) as ilhas; f) o lagote; g) as capoeiras; $h$ ) o igarapé; i) os lagos e; j) a terra firme (Figura 5; Quadro 1). 


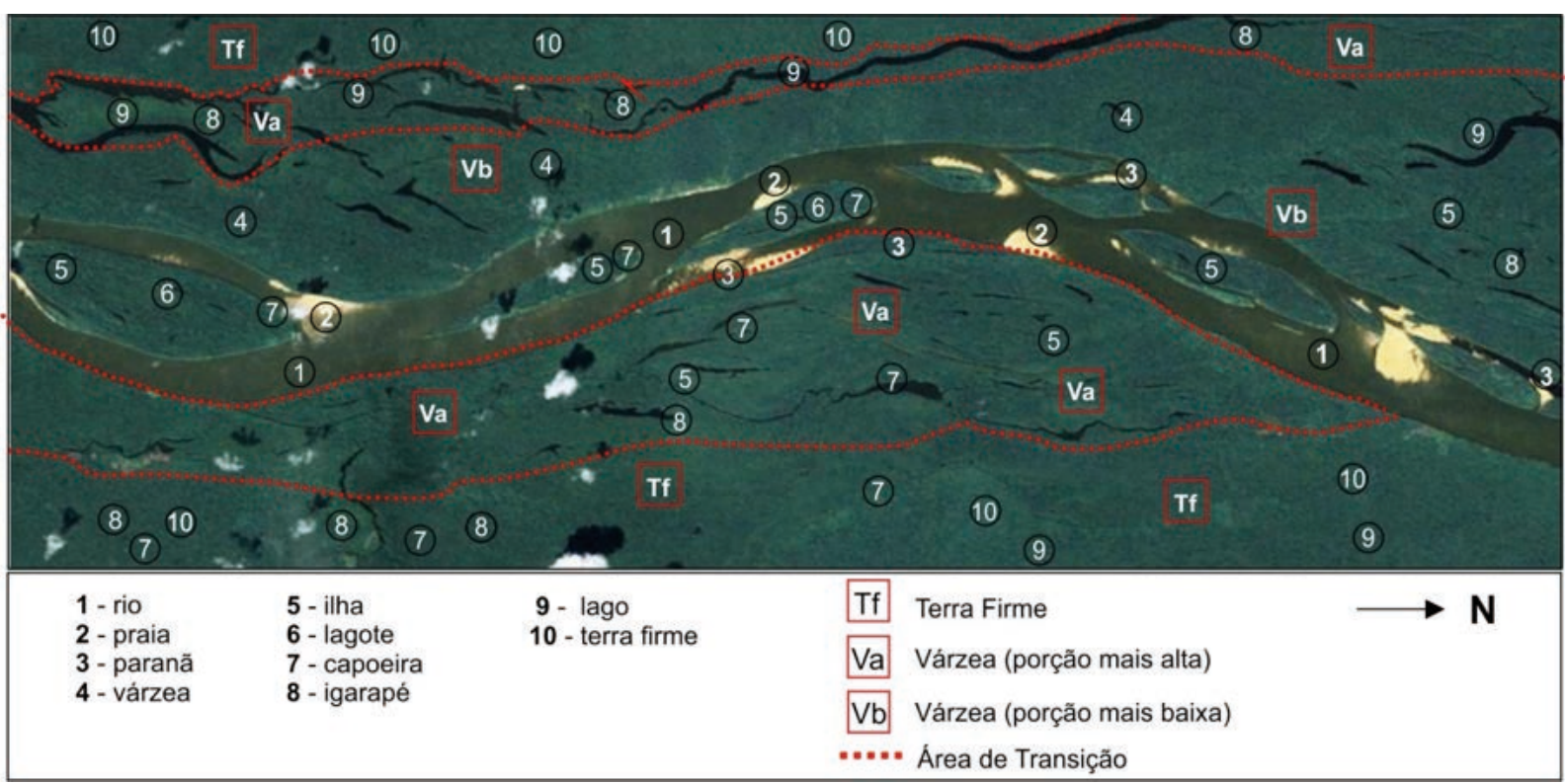

Figura 5 - Imagem Landsat 5 com marcação das unidades de paisagem, na paisagem de seca, pelos sujeitos em atividade de grupo focal.

Fonte: Organizado pelos autores.

O rio aparece primeiramente como elemento temporal, uma vez que é indicador do pulso das águas. Em segundo, aparece como unidade de paisagem que nos períodos de seca apresenta a sua calha com maior definição. Para os sujeitos, o rio é o meio pelo qual se dá o deslocamento das famílias para as cidades de Manaus e Caracaraí.

As praias e paranãs são unidades diretamente relacionadas ao rio e sua calha. Para Boulhosa e Mendes (2007, p. 3), as praias são depósitos arenosos, com menor largura e extensão, constituídos por sedimentos de granulometria fina a média, ricos em quartzo e minerais densos. No caso do Rio Branco, a formação das praias está relacionada ao período de estiagem dos rios (Carvalho, 2014, p. 93). Segundo um dos sujeitos, as praias apresentam dinâmica própria, onde mudam de lugar entre um ano e outro (Figura 6G; Quadro 1 ).

Já os paranãs são canais mais estreitos no rio, com menor interferência das correntes e que podem ligar duas partes de terra em um espaço de tempo mais curto, como um atalho (Figura 6D). Para Noda et al. (2012, p. 402), o paranã ou paraná aparece caracterizado em um dos dísticos dos seus sujeitos como um rio pequeno que não oferece muito perigo, não tem banzeiro e pode ser acessado tanto por canoa grande quanto pequena. Segundo um dos dísticos dos sujeitos do Complexo Ambiental Sacaí, os paranãs são característicos da época de seca e posicionam-se fora do canal principal (Quadro 1). 
Quadro 1 - Nomenclatura e conceituação social das unidades de paisagens no período de seca, no Complexo Ambiental Sacaí, município de Caracaraí, estado de Roraima, Brasil, 2016/2017.

\begin{tabular}{|c|c|}
\hline \multicolumn{2}{|r|}{ Paisagem de seca } \\
\hline $\begin{array}{c}\text { Unidades de } \\
\text { paisagem }\end{array}$ & Disticos \\
\hline \multirow[b]{2}{*}{ Rio } & "[...] o rio é muito bonito, é toda essa fartura ai" (A.B.S., 65 anos, Complexo Ambiental Sacai). \\
\hline & $\begin{array}{l}\text { "[...] a água para beber e também para gente transitar daqui para cidade" (S.J.S., } 34 \text { anos, Complexo } \\
\text { Ambiental Sacai). }\end{array}$ \\
\hline Praia & $\begin{array}{l}\text { "[...] o senhor está vendo essa praia aqui? Ela estava ali atrás naquela illha e esse ano já está aqui na } \\
\text { frente. [...] essa que estava aqui já está ali perto do Água Boa, ali na frente, e por aí vai" (A.B.S., } 65 \text { anos, } \\
\text { Complexo Ambiental Sacaí). }\end{array}$ \\
\hline Paranã & $\begin{array}{l}\text { "[...] quando tem o paranã é mais făcil, você pega o paranã e em vez de fazer o canal você corta pelo } \\
\text { paranã. Aquele caminho que você tira em uma hora, pelo paranã você tira em trinta minutos, vamos } \\
\text { dizer" (A.B.S., } 65 \text { anos, Complexo Ambiental Sacai). }\end{array}$ \\
\hline Ilha & $\begin{array}{l}\text { "[...] se o senhor precisar atravessar o rio e dá um banzeiro, você não precisa nem se preocuparporque } \\
\text { pode ficar na ilha, porque o rio é estreito" (A.B.S., } 65 \text { anos, Complexo Ambiental Sacaí). }\end{array}$ \\
\hline Lagote & $\begin{array}{l}\text { "[...] nas ilhas têm lago sim, é lagote, é pequeno. [...] se tem peixe?! Mas rapaz, lá ćonde temmesmo! } \\
\text { [...] é assim, é que eles não conseguem sair ai fica tudo preso lá" (J.M.N.S., } 30 \text { anos, Complexo } \\
\text { Ambiental Sacai). }\end{array}$ \\
\hline Igarapé & "o igarapé é um lago" (J.N.S., 27 anos, Complexo Ambiental Sacai) \\
\hline \multirow{2}{*}{ Lago } & $\begin{array}{l}\text { "[...] o lago ć tipo o rio sabe, não é da largura do rio, mas a água é limpa, aí tem uns cantos quetem } \\
\text { igapó" (A.J.Q., } 65 \text { anos, Complexo Ambiental Sacai). }\end{array}$ \\
\hline & "[...] o lago tem peixe, é largo e a gente vai só pescar né!" (J.C.A., 50 anos, Complexo Ambiental Sacai). \\
\hline \multirow{3}{*}{ Terra Firme } & $\begin{array}{l}\text { "[...] é importante porque não alaga. Estando na terra firme ele está seguro. Quando você tem cria na } \\
\text { terra firme é melhor" (A.B.S., } 65 \text { anos, Complexo Ambiental Sacaí). }\end{array}$ \\
\hline & $\begin{array}{l}\text { "[...] a terra firme é assim: _ficou só eu na alagação [na várzea] porque tem dois pisos,o resto foi paraa } \\
\text { terra firme" (A.S.M; } 38 \text { anos, Complexo Ambiental Sacai). }\end{array}$ \\
\hline & $\begin{array}{l}\text { "[...] a terra firme, ela é, (pausa) nós vivemos mais por causa dela, se não tivesse terra firme eu estava } \\
\text { doidinho. A terra firme é uma mão para nós. Na cheia ela guarda os animais e na seca ela manda para } \\
\text { gente" (J.N.S., } 27 \text { anos, Complexo Ambiental Sacai). }\end{array}$ \\
\hline \multirow[t]{2}{*}{ Capoeira } & $\begin{array}{l}\text { "[...] geralmente, agente planta duas vezes, principalmentea mandioca. Planta duas vezes num só local, } \\
\text { ai a terra já fica mais fraca, ai a gente deixa ela ficar mais e se reproduzir a vegetação para poder roçar de } \\
\text { novo. A gente sempre deixa [...] com um ano, dois anos, ai já está a capocira grande de novo [...] a } \\
\text { juquira, como chama" (E.C.A., } 58 \text { anos, Complexo Ambiental Sacai). }\end{array}$ \\
\hline & $\begin{array}{l}\text { "[...] não planta, não é bom, aí nós vamos varar em outro lugar. [...] não utilizo capoeira não, porque } \\
\text { nasce muito mato" (D.A.S., } 76 \text { anos, Complexo Ambiental Sacai). }\end{array}$ \\
\hline
\end{tabular}




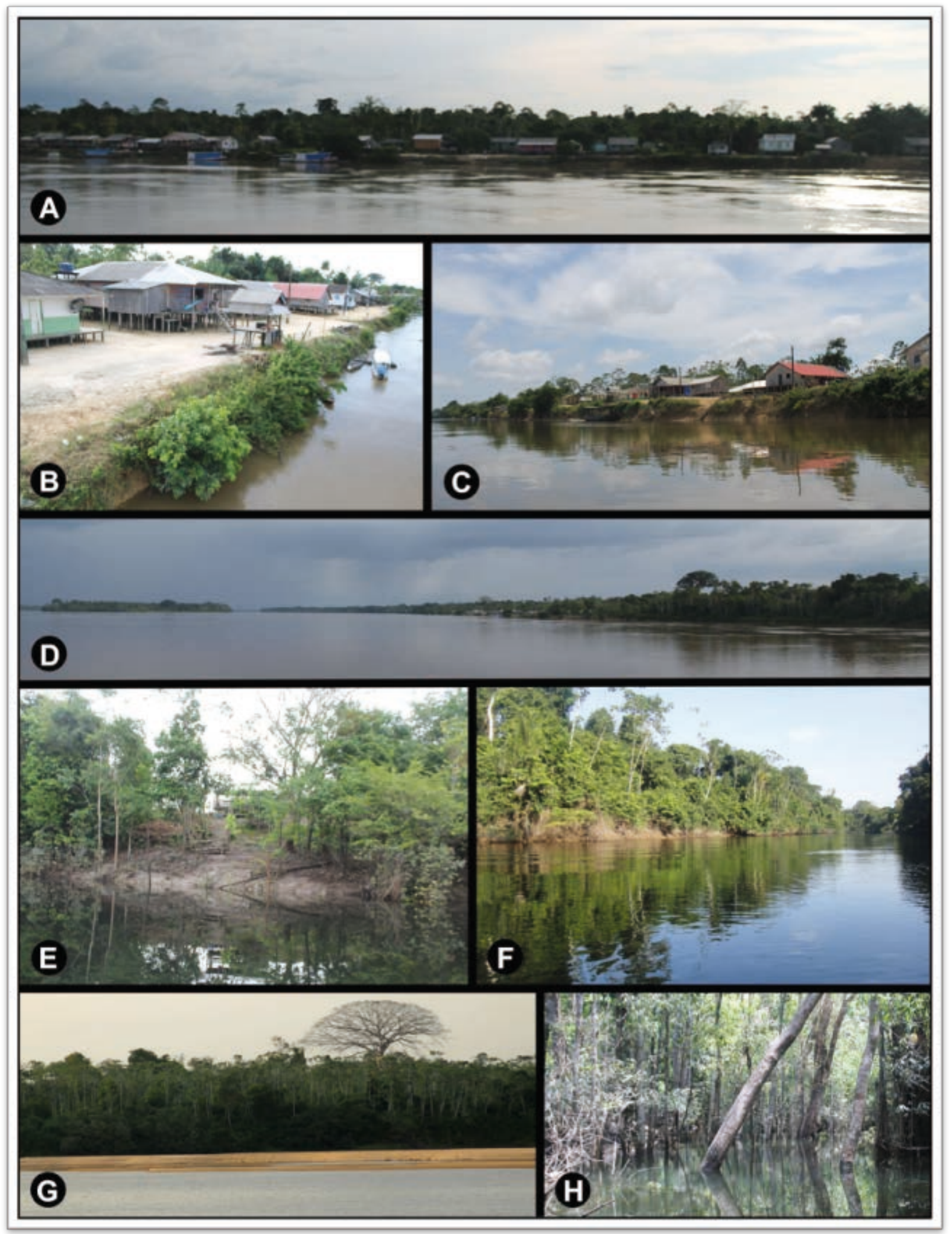

Figura 6 - Representações fotográficas da sede do Complexo Ambiental Sacaí na paisagem de seca (A, B e C); Várzea, ilha e paranã no Rio Branco (D); Terra firme no igarapé Água Boa (E); Lago do Pacu, próximo ao igarapé do Castanho (F); Praia no Rio Branco (G) e Igarapé Água Boa (H). Complexo Ambiental Sacaí. Município de Caracaraí. Estado de Roraima. Brasil 2015.

Fonte: Fotografias e organização pelos autores. 
As várzeas também compõem a paisagem de seca (Figura 6D). Nesse período, está exposta e apresenta extensas continuidades de terra, caracterizando-se como ambiente essencialmente terrestre. Para Junk et al. (2014, p. 12), as várzeas encontram-se em um grupo de ecossistemas relacionados à periódica inundação, convencionado por áreas úmidas, representativas a 30\% das terras do planeta. Nesse sentido, a conceituação das áreas úmidas aparece da seguinte forma:

\begin{abstract}
[...] as áreas úmidas são ecossistemas com interfaces aquáticas e terrestres; elas podem estar contidas no continente, ou em áreas costeiras; periodicamente ou permanentemente inundadas. A composição das águas vai de doce até altamente salinizada. As áreas úmidas apresentam específicas espécies vegetais e animais e dinâmica hidrológica, desde a amplitude de enchente e seca. As áreas encharcadas apresentam caracteristicamente espécies lenhosas capazes de viver permanente ou parcialmente inundadas. Ainda, como característica de áreas úmidas, aparecem as áreas mais altas, secas, extremamente importante para a manutenção da biodiversidade e integridade da respectiva área úmida (Junk et al., 2014, p. 12).
\end{abstract}

É na várzea que está localizada a sede do Complexo Ambiental Sacaí (Figuras 6A, B e C). Em virtude da importância que assume na composição da paisagem de cheia, a relação entre a disposição das casas e a várzea será discutida detalhadamente no item "A paisagem de cheia".

Na paisagem de seca, com as águas baixas, todas as terras podem ser vistas. Dessa forma, outra unidade que se faz visível é a ilha a qual se define como faixas de terra descontinuadas dentro do canal do rio, com altitude similar às várzeas (Figura 6D). As visões de mundo referentes às ilhas revelam a possibilidade de apoio ao transitar entre as margens sem precisar se preocupar com as intempestividades do rio.

A descrição altimétrica das ilhas, segundo o mapa mental de um dos sujeitos (Figura 4), mostra essa unidade apresentando suas porções de terra mais altas nas bordas e mais baixas no centro. Nos períodos de cheia, as ilhas, como unidade de paisagem, desaparecem uma vez que ficam submersas. Na vazante, parte das águas da cheia anterior ficam aprisionadas nas porções mais baixas de terra da ilha, formando o que os sujeitos denominam por lagote. Como produto dessa dinâmica, o lagote figura como uma das principais fontes de peixes no período de pesca.

Para Ferreira et al. (2007, p. 85), esses tipos de lagos apresentam o mesmo comportamento de lagos de diques, são temporários e somente acontecem desde a existência de períodos de alagação.

Afastando-se da calha do rio em direção às várzeas, é possível identificar canais que desembocam diretamente no Rio Branco, os igarapés (Figura 6H). Segundo um dos sujeitos, "o igarapé é um lago" (J.N.S., 27 anos, Complexo Ambiental Sacaí). Para Carvalho (2014, p. 90), o rebaixamento dos sistemas fluviais Uraricoera e Tacutu está diretamente relacionado à morfologia apresentada no Rio Branco, o qual apresenta características de lagos e igarapés interconectados durante toda sua extensão. Os lagos no Complexo Ambiental Sacaí são os próprios igarapés (Figura 6F). Segundo Carvalho (2014, p. 92), dos 842 lagos contabilizados no Rio Branco, 651 estão localizados no Baixo Rio Branco. Para os sujeitos, os lagos apresentam formas mais alargadas, com maior profundidade do que os igarapés descritos e reconhecidos anteriormente. Diferentemente dos lagotes, os lagos apresentam-se como sistemas abertos, com ligação direta com os rios e com distinção na coloração das águas.

A diversidade de coloração das águas aparece no estudo de Santiago (2015, p. 43) em coletas feitas no Complexo Ambiental Sacaí, a partir de diferentes índices de turbidez. De acordo com os resultados, o Rio Branco apresentou maior índice de turbidez (13,6 - 19,1 NTU) sendo seguido pelo Lago Limão (7,92 NTU), o igarapé Castanho (4,55 NTU) e o igarapé Água Boa (1,41 NTU). O reconhecimento das diferenças das águas no Complexo Ambiental Sacaí dá condições de entender as diferentes composições de unidades de paisagem no Complexo Ambiental Sacaí desde as visões de mundo.

Na paisagem de seca do Complexo Ambiental Sacaí evidenciaram-se também inalteradas em relação ao pulso das águas, denominadas por terra firme (Figura 6F). As terras firmes ocupam as extremidades do Complexo Ambiental Sacaí e, conforme já mencionado, caracterizam-se por apresentar terras mais altas do que as demais. Para Sioli (1984, p. 141) e Vicentini (2001, p. 143), por esse motivo não estão sujeitas a inundações periódicas.

Nas partes de terra firme estão situados alguns sítios e, com pequena frequência, roças. A terra firme 
surge normalmente por detrás das áreas de várzea e são responsáveis por delimitar os vales dos rios (Sioli, 1983, p. 27). Essa unidade de paisagem revela-se, a partir das visões de mundo, como o local cujo propósito é resguardar as famílias que moram na várzea durante os períodos das maiores cheias, ou seja, na alagação.

Assim, mesmo a terra firme não figurando como principal local de moradia dos sujeitos, é possível identificá-la como elemento imprescindível em relação ao processo de reprodução social existente no Complexo Ambiental Sacaí.

Finalmente, há unidades de paisagem que surgem a partir da interação do homem com o ambiente, como é o caso de porções de terra apresentando vegetação destoante da continuidade da floresta. Essa unidade é denominada capoeira e está relacionada a uma nova vegetação estabelecida nos espaços onde foram cultivadas as antigas roças.

As visões de mundo dos sujeitos revelam o trabalho da roça na capoeira diretamente relacionado à necessidade de recuperação dos nutrientes do solo. Por outro lado, em virtude da regeneração da mata, após um período de repouso, essa área nem sempre volta a ser utilizada.

As capoeiras, hoje, na paisagem de seca do Complexo Ambiental Sacaí estão mais presentes na porção de terra firme, pois fazem referência a antigas áreas de roça que foram abandonadas considerando estratégias de adaptabilidade (MORÁN, 2010, p. 39) existentes para composição de novas roças. Conforme tratado acima, a paisagem de seca é caracterizada pela maior exposição de unidades de paisagem terrestres, a partir da vazante. Ela é definida desde o pulso das águas e intercala-se recursivamente com uma outra paisagem, a paisagem de cheia.

\section{A PAISAGEM DE CHEIA}

"[...] na cheia, de terra firme a terra firme, é tudo água". (J.N.S., 27 anos, Complexo Ambiental Sacaí).

A paisagem nos períodos de cheia, ao contrário dos períodos de seca, é caracterizada pela continuidade das águas e revela-se a partir das visões de mundo com uma configuração composta pelas seguintes unidades de paisagem: a) rio; b) várzea; c) igapó; d) cano; e) restinga; f) terra firme e g) capoeira (Quadro 2). Entre elas, tanto a terra firme quanto a capoeira não sofrem modificações em relação à paisagem de seca (Figuras 7 e 8).

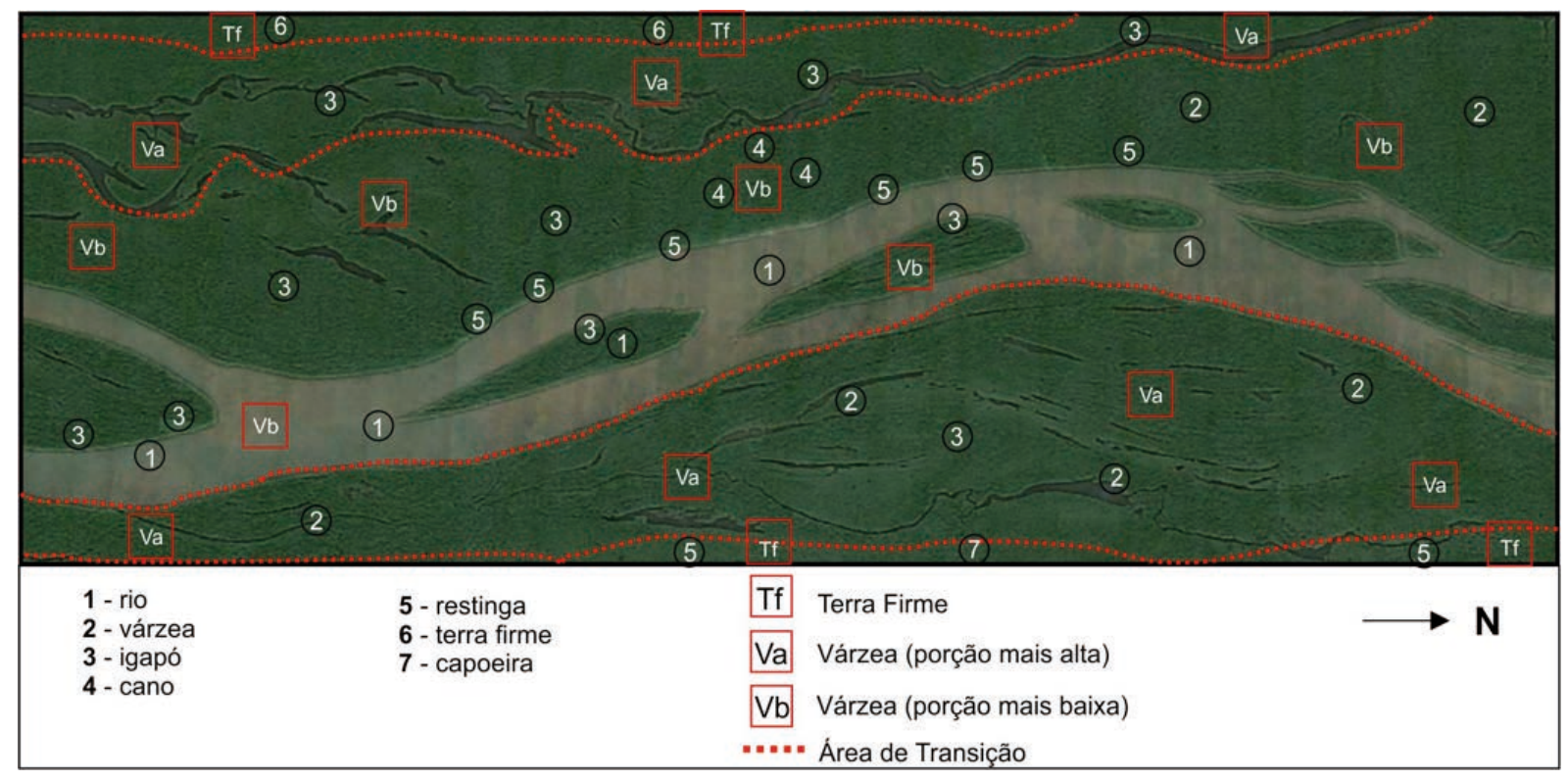

Figura 7 - Imagem Landsat 5 com marcação das unidades de paisagem, na paisagem de cheia, pelos sujeitos em atividade de grupo focal. Complexo Ambiental Sacaí. Município de Caracaraí, estado de Roraima, Brasil 2015. 
Nesse período, o rio caracteriza-se pelo seu extravasamento e por ocupar faixas de terras mais baixas, as várzeas. $\mathrm{O}$ mesmo extravasamento ocorre com os lagos e igarapés, cujas águas se unem formando um continuum, escondendo unidades de paisagem que haviam sido expostas na seca.

Na ocasião do extravasamento dos igarapés, dos lagos e da inundação das faixas de terra mais baixas e circundantes, formam-se os igapós. Segundo o dístico de um dos sujeitos apresentado no Quadro 2, essa unidade de paisagem é representada pela vegetação típica da várzea, embaixo da água (Figuras 8B e D).

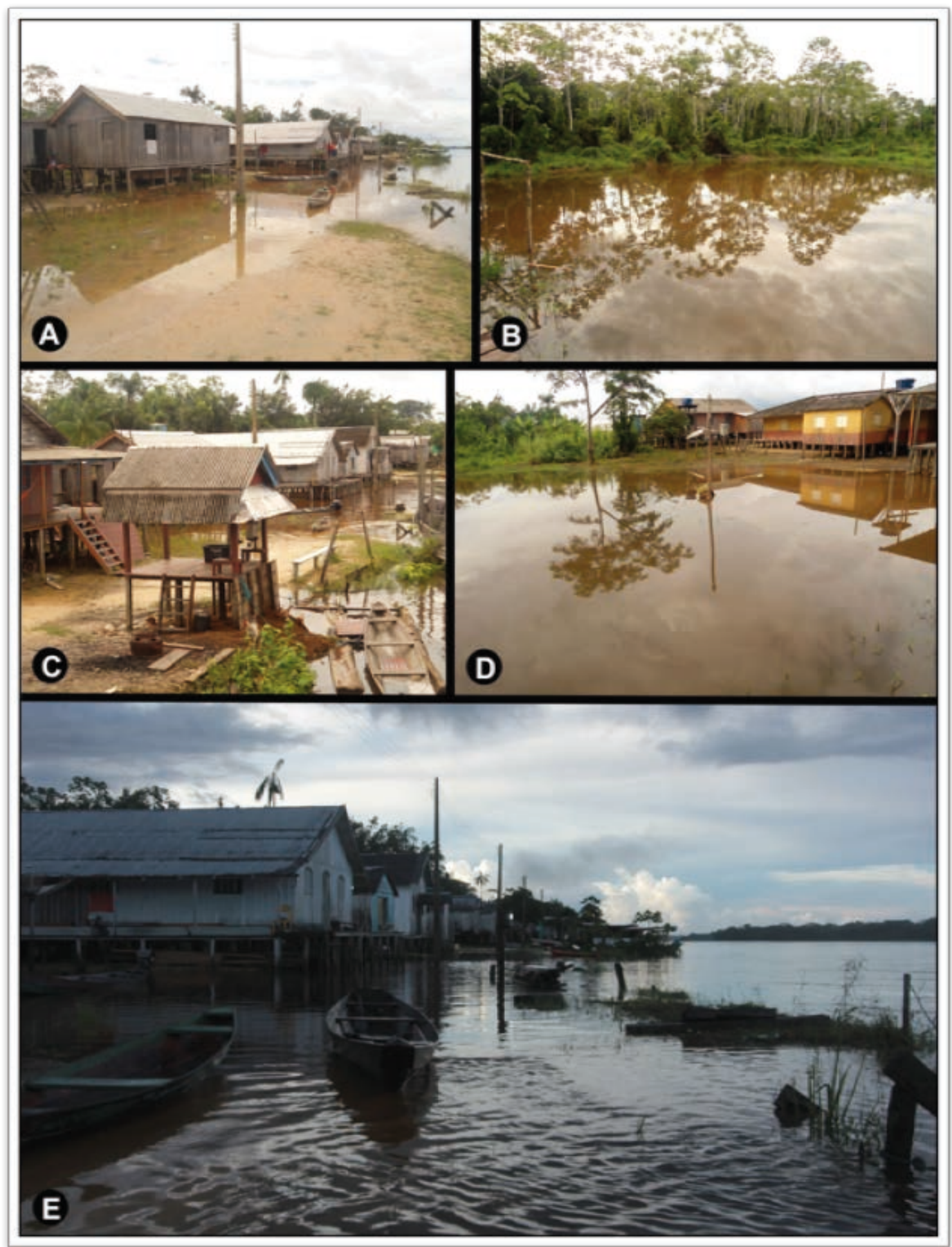

Figura 8 - Representações fotográficas da sede do Complexo Ambiental Sacaí na paisagem de cheia: a restinga, a última porção de terra a alagar, vista a partir do Rio Branco ( $A, C$ e E) e vista a partir do fundo das residências (B e D). Complexo Ambiental Sacaí. Município de Caracaraí. Estado de Roraima. Brasil 2015. 
Nos períodos de cheia, quando as várzeas começam a ser tomadas pelas águas, mesmo que ainda sem atingir as maiores cotas fluviométricas, começam a surgir estreitos canais de drenagem os quais possibilitam o acesso rápido até a alguns lagos. Esses canais são denominados de cano. Segundo um dos sujeitos, os canos são importantes meios para o deslocamento com acesso direto aos destinos, e atuam como atalhos (Figura 3).

\begin{tabular}{|c|c|}
\hline \multicolumn{2}{|r|}{ Paisagem de cheia } \\
\hline $\begin{array}{l}\text { Unidades de } \\
\text { paisagem }\end{array}$ & Disticos \\
\hline \multirow[b]{2}{*}{ Igapó } & "[...] a várzea é tudo igapó" (J.N.S., 27 anos, Complexo Ambiental Sacai). \\
\hline & $\begin{array}{l}\text { "[...] o igapó é no lago, é porque a várzea é baixa né, ai fica aquele igapó até onde tem terra mesmo, } \\
\text { e a gente chama o igapó. [...] na beirada dele cobre a várzea todinha é igapó, aí vai vazando as } \\
\text { poucos vai descobrindo as várzeas" (A.J.Q., } 65 \text { anos, Complexo Ambiental Sacai). }\end{array}$ \\
\hline Cano & $\begin{array}{l}\text { "[...] a importância do cano é porque você não precisa dar volta" } \\
\text { Ambiental Sacaí). }\end{array}$ \\
\hline Restinga & $\begin{array}{l}\text { "[...] alagado porque aí a terra cobre e ficam só aquelas terras mais altas, ai fica todo mundo ai } \\
\text { preso né? a importância da restinga é porque ficam todos os bichos" (A.B.S., } 65 \text { anos, Complexo } \\
\text { Ambiental Sacai). }\end{array}$ \\
\hline Várzea & $\begin{array}{l}\text { "[-..] a várzea é melhor de planta, mas a desvantagem é porque alaga, mas tudo na várzea émais } \\
\text { vistoso" (J.N.S., } 27 \text { anos, Complexo Ambiental Sacai). }\end{array}$ \\
\hline
\end{tabular}

Quadro 2 - Nomenclatura e conceituação social das unidades de paisagens no período de cheia no Complexo Ambiental Sacaí, município de Caracaraí, estado de Roraima, Brasil, 2016/2017.

Fonte: Organizado pelos autores.

Seguindo-se o ciclo da enchente, quando o volume hídrico começa a atingir sua maior cota e quando quase tudo já está tomado por águas, nas várzeas, somente algumas porções de terras mais altas ainda permanecem expostas. Essas porções de terras são denominadas de restinga.

É na restinga onde a sede do Complexo Ambiental Sacaí está situada, ou seja, na porção mais alta da várzea, à margem direita do Rio Branco. A alocação das casas nessa unidade de paisagem é estratégica, pois se trata do último local da várzea a ser tomado por águas nos períodos de cheia. As casas estão dispostas linearmente e apresentam estruturas em madeira e seguem a arquitetura de palafitas (Figura 8). A disposição linear das casas na restinga remete a estratégias de conservação e adaptabilidade (MORÁN, 2010; MORIN, 2011) acessadas desde a compreensão da paisagem nos períodos de cheia. Para Simonian (2010, p. 6), as construções de casas em palafitas apresentam estreita relação com o ambiente. Assim, a restinga, além do lugar de moradia, é o lugar mais fértil e vistoso.

\section{CONCLUSÃO}

Conforme se pode observar, o revelar das paisagens de seca e de cheia dá-se a partir das variadas escalas de compreensão, em dimensionalidade própria atrelada ao real, como um híbrido entre a materialidade e imaterialidade. Como materialidade se pode considerar, por exemplo, a geomorfologia local, e como imaterialidade as percepções topofílicas, responsáveis por se apropriar dessa materialidade e dissipá-la a partir de processos (re)construtivos. O caminho teórico em relação à categoria de análise da paisagem é avançado e necessário para entender a produção do espaço na multidimensionalidade têmporoespacial, porém, ainda incapaz de trazer o enlace das interações e compreender a circularidade do saber ambiental necessário para novas estruturas de conservação.

Nesse sentido, é impossível, desde a episteme atual, considerar a apreensão de fenômenos recursivos da vida a partir de ferramentas pontuais. Tampouco, a descrição das paisagens a partir de suas unidades pode ser considerada suficiente para a apreensão do todo. Assim, a compreensão do ambiente, por meio da imaterialidade exposta pelos agricultores familiares do Complexo Ambiental Sacaí, é parte 
imprescindível na organização de possíveis novas estratégias (i)materiais de uso das unidades de paisagem. Nesse sentido, a unidade de paisagem é meio de dispersão da (i)materialidade, assim como meio de construção para uma nova configuração (i)material.

\section{REFERÊNCIAS}

BALÉE, W. The research program of historical ecology. Cadernos do Lepaarq, v. 14, p. 180212, 2017. Disponível em: <https://periodicos.ufpel.edu.br/ojs2/index.php/lepaarq/article/ download/12675/7943>. Acesso em: 5 abr. 2018.

BOULHOSA, M. B. M.; MENDES, A. C. Mapeamento da paisagem na área de influência do Porto de Vila do Conde, Barcarena, Pará. In: CONGRESSO BRASILEIRO DA ABEQUA, 2007, Belém. Anais... Belém, 2007.

CARLOS, A. F. A. O espaço urbano: novos escritos sobre a cidade. São Paulo: Labur Edições, 2007.

CARVALHO, T. M. Sistemas e ambientes denudacionais e agradacionais, uma primeira aproximação para o estado de Roraima, norte da Amazônia. Acta Geográfica. UFRR, v. 8, p. 77-98, jan/mar 2014. Disponível em: <https://revista.ufrr.br/actageo/article/view/2452/1482>. Acesso em: 5 abr. 2018.

CLAVAL, P. A geografia cultural. Florianópolis: Editora da UFSC, 2014.

COMPANHIA DE PESQUISA DE RECURSOS MINERAIS. Dados pluviométricos e fluviométricos. Boa Vista: CPRM - Serviço Geológico do Brasil, 2017.

FERREIRA, E. et al. Rio Branco: peixes, ecologia e conservação de Roraima. Manaus: INPA, 2007.

FUNDAÇÃO ESTADUAL DO MEIO AMBIENTE, CIÊNCIA E TECNOLOGIA DE RORAIMA. Plano de Estruturação do Sistema de Gerenciamento de Recursos Hídricos do estado de Roraima. Volume II. Boa Vista: Simões Engenharia, 2007a.

FUNDAÇÃO ESTADUAL DO MEIO AMBIENTE, CIÊNCIA E TECNOLOGIA DE RORAIMA. Plano de Estruturação do Sistema de Gerenciamento de Recursos Hídricos do estado de Roraima. Volume III. Boa Vista: Simões Engenharia, 2007b.

JUNK, W. J.; BAYLEY, P. B.; SPARKS, R. E. The flood pulse concept in river floodplain systems. Canadian Journal of Fisheries and Aquatic Sciences, v. 106, p. 110-127, set. 1989. Disponível em: <https://www. nrem.iastate.edu/class/assets/aecl518/Discussion\%20Readings/Junk_et_al._1989.pdf>. Acesso em: 5 abr. 2018.

JUNK, W. J. et al. Brazilian wetlands their definition, delineation and classification for research, sustainable management, and protection. Aquatic Conservation (Print). v. 24, p. 5-22, 2014. Disponível em: <http://www.ib.usp.br/zoologia/seminarios/Seminarios-USP/Curso_BIZ5755_(2015)_files/ aqc2386.pdf>. Acesso em: 5 abr. 2018.

MEtZGER, J. P. O que é ecologia de paisagens? Biota Neotrópica, v. 1, p. 1-9, 2001. Disponível em: <http://www.scielo.br/pdf/bn/v1n1-2/a06v1n1-2.pdf>. Acesso em: 5 abr. 2018.

MORÁN, E. Adaptabilidade humana: uma introdução à antropologia ecológica. 2 ed. rev. e ampl. São Paulo: Senac, 2010.

MORIN, E. O método II: a vida da vida. Porto Alegre: Sulina, 2011.

NODA, S. N. et al. Paisagens e etnoconhecimentos na agricultura Ticuna e Cocama no Alto Rio Solimões, Amazonas. Bol. Mus. Para. Emílio Goeldi. maio-agosto 2012, vol. 7, Ciências Humanas, p. 397-416, 2012. Disponível em: <http://www.scielo.br/pdf/bgoeldi/v7n2/v7n2a06.pdf>. Acesso em: 5 abr. 2018. 
SANTIAGO, E. R. M. Diagnóstico da qualidade da água utilizada para consumo humano na região do Baixo Rio Branco, Caracaraí, Roraima. 2015. Monografia (Licenciatura em Química) - Universidade Estadual de Roraima, Boa Vista. 2015.

SIMONIAN, L. T. L. Palafitas, estivas e sua imagética na contemporaneidade urbano-rural da PanAmazônia. Papers do Naea. NAEA/UFPA, Belém. Junho 2010. Disponível em: <http://www.naea.ufpa. $\mathrm{br} /$ naea/novosite/index.php?action=Publicacao.arquivo\&id=329>. Acesso em: 5 abr. 2018.

SIOLI, H. The Amazon and its main afluents: hidrography, morphology of the rivers courses, and rivers types. In: (Ed.). Amazon: limnology and landscapes ecology of a mighty tropical rivers and its basin. Dordrecht, Netherlands: Dr. W. Junk, 1984. p. 127-166.

. Amazônia: fundamentos da ecologia da maior região de florestas tropicais. Petrópolis: Editora Vozes, 1983.

STERNBERG, H. O. R. A água e o homem na várzea do Careiro. Belém: Museu Paraense Emílio Goeldi, v. 2, 1998.

TUAN, Y-F. Topofilia: um estudo da percepção, atitudes e valores do meio ambiente. Londrina: Eduel, 2012.

VERDEJO, M. E. Diagnóstico rural participativo: guia prático DRP. Brasília: Secretaria de Agricultura, 2006.

YIN, R. Estudo de caso: planejamento e métodos. Porto Alegre: Bookman, 2014. 